\title{
The cognitive power of product Packaging
}

\author{
Abhilasha Pathak \\ Asst. Professor, Faculty of Commerce \& Humanities, Manav Rachna International University, Faridabad, India
}

\begin{abstract}
As human beings require Power dressing to shape up their personality likewise is also required by a product. In the research paper below it is described how packaging of the product is influenced by its cognitive power. The mental processes of knowing, perceiving, remembering, reasoning \& judgement affects the success of product packaging \& ultimately affects the leadership potential of the brand. Imagine a product without a dress, so how haphhazard it would be for the consumers to know \& identify a right product for them. Again if some products are wrapped in a shabby pack and some in clean, attractive, stylish packs which product the consumer would pick first? Obviously the one which is packed in a style. Marketers have not only provided a basic wrap but also have upgraded it from time to time to give a more appealing,stylish \& formal look to the product in order to make the product more responsible, accountable \& incredible in the eyes of the customer.Packaging gives a opportunity to influence the customers which ultimately may result in final purchase of the product. More cognitive power is added to the product package, more the customer will associate themselves to the product. A simple framework is discussed through this paper related to these mental processes through which the consumer identifies a product, recognise it, memorise it and builds a stong intention to purchase the product.
\end{abstract}

Kotler defines packaging as "all the activities of designing and producing the container for a product."

And the package includes the primary container, like the tube of toothpaste and the bottle of perfume; the secondary package is thrown away when the product is used, like wrapping paper; and the shipping package which uses for transportation to store. (Philip Kotler et al. 2005 p. 550)

Orth and Malkewitz (2008)'s definition of package design as "the various elements chosen and blended into a holistic design to achieve a particular sensory effect, which is based on the principles of Gestalt psychology (Koffka 1922) and work on design theory (Bloch 1995, Veryzer 1999) judgement.

The word 'cognitive' refers to the mental process of knowing, perceiving, remembering, reasoning \&

Besides serving the basic function of preserving the product, protecting the product from any damage during transportation or on the shelf, increasing self-service by providing adequate information to the customers about the product Packaging is also used as a sharp edged weapon which ultimately helps the prospect to build a good image, a positive perception \& a reason to buy a brand of poduct. This however may give the answere to the question that"why do some brands stuck in their careers while the other brands succeeds?" On the contrary the product can face several rejection from the consumers \& can bring bad luck to the brand if the package is not designed in a thoughtful way.

In a review paper Fitzsimons et al (2002) posit that consumer choice behavior is a mix of conscious and nonconscious influences, and the role of nonconscious influences may be quite significant. They define nonconscious influences to include stimuli that are not consciously perceived by the consumer, downstream effects of consciously perceived stimuli, and decision processes that occur entirely outside of awareness.

Through this paper a simple framework to evaluate the cognitive power of packaging is discussed and is called "IDEAL"

\section{I: Intellectual}




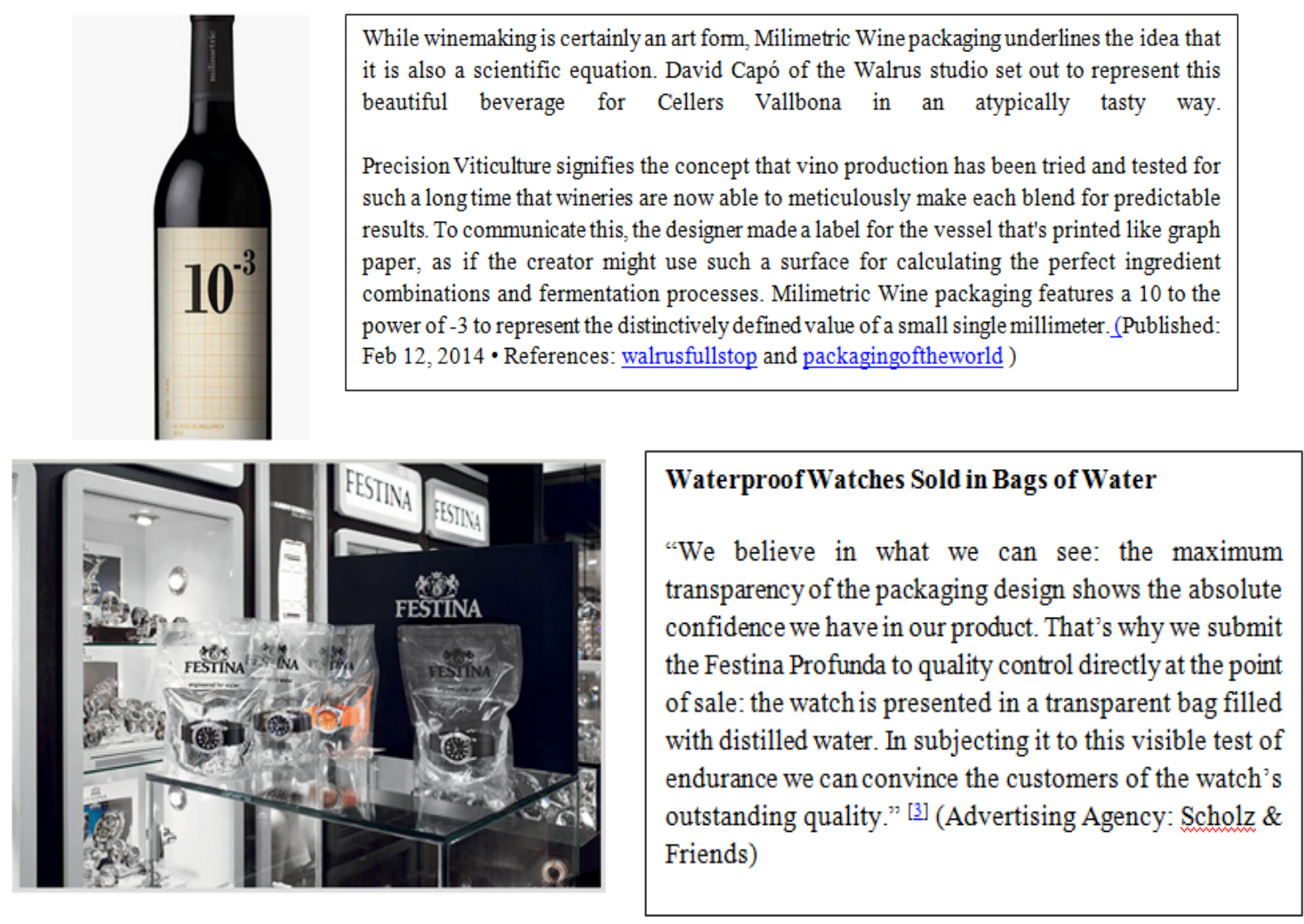

As self-service marketing is gaining importance day-by-day, the cognitive power of packaging is becoming quite significant. Red colour package of Colgate sensitive toothpaste, for instance, differentiates it with other brands of the product as well as provides more visibility to the product. Silayoi and Speece (2004) named packaging as 'the salesman on the shelf' to emphasize its marketing power(Silayoi and Speece 2004). If a customer does not notice a brand's physical existence on shelf then the brand is not mentally available (Sharp, 2010). For example, in a typical supermarket how to make the consumers notice the product when a shopper passes through 700 different products at a time. So Innovative Packaging provides more visibility \& attention to a organisation's products by making the consumer feel the presence of the product on the retail shelf as well as in their homes. For instance, Kelloggs cornflakes, a breakfast cereal package can make its presence felt on the retail shelf as well as on the breakfast table every morning, through its intellectual designs, use of quality packaging material which keeps the freshness \& quality of the product intact, in a more meaningful way and can enjoy top of the mind awareness \& easily become a part \& parcel of the family.

Intellectual packaging is the need of the hour to generate likeability, strong affinity of the customer towards the product encouraging consumer affluence. Besides converting a consumer's intention to purchase a brand into final purchase of the brand sometimes it also makes the consumer switch brands ultimately creating a new customer for the organization by turning a non-user to a user. Packaging includes labeling, graphics, colors, designs, etc., and is important because it is the introduction of a company's product to a consumer (Volpe, and Koenig, p.38). One way to create a unique product in the minds of consumers is through trade dress which is unique packaging, labeling, etc.. Trade dress is protected by trademark law and must designate a single source, a product associated with one company (Volpe and Koenig, pp.39-40)

\section{D: Distinct}

Kotler (2003) distinguishes six elements that according to him must be evaluated when employing packaging decisions: size, form, material, color, text and brand. Cognitive power of packaging helps the target demographic to understand \& differentiate the brand from the other in a meaningful manner. The orange colour of Tang, for instance, makes it different from the other brands. How quickly \& effectively the package can communicate and build differentiating segments in the mind of the consumer through its features \& attributes, the brand logo, color \& other significant characterstics affects the leadership potential of the product in the market which ultimately impacts the sales of the product. The consumers must be able to differentiate the brands of the product through their packaging style and must perceive the differences useful for them. Coke $\&$ pepsi, for instance, if served in glass looks alike \& one cannot do distinction between the two. The differentiation \& distinction between the two comes through Packaging,i.e, the bottles in which they are offered by the 
organization. Likewise what makes Dettol \& Lifebuoy Handwash distinct? It is the type, style, color of the container in which they are packed. However the product offered is almost the same but they both maintain their uniqueness through packaging. So Packaging makes or destroys the first impression of the customer about the product.

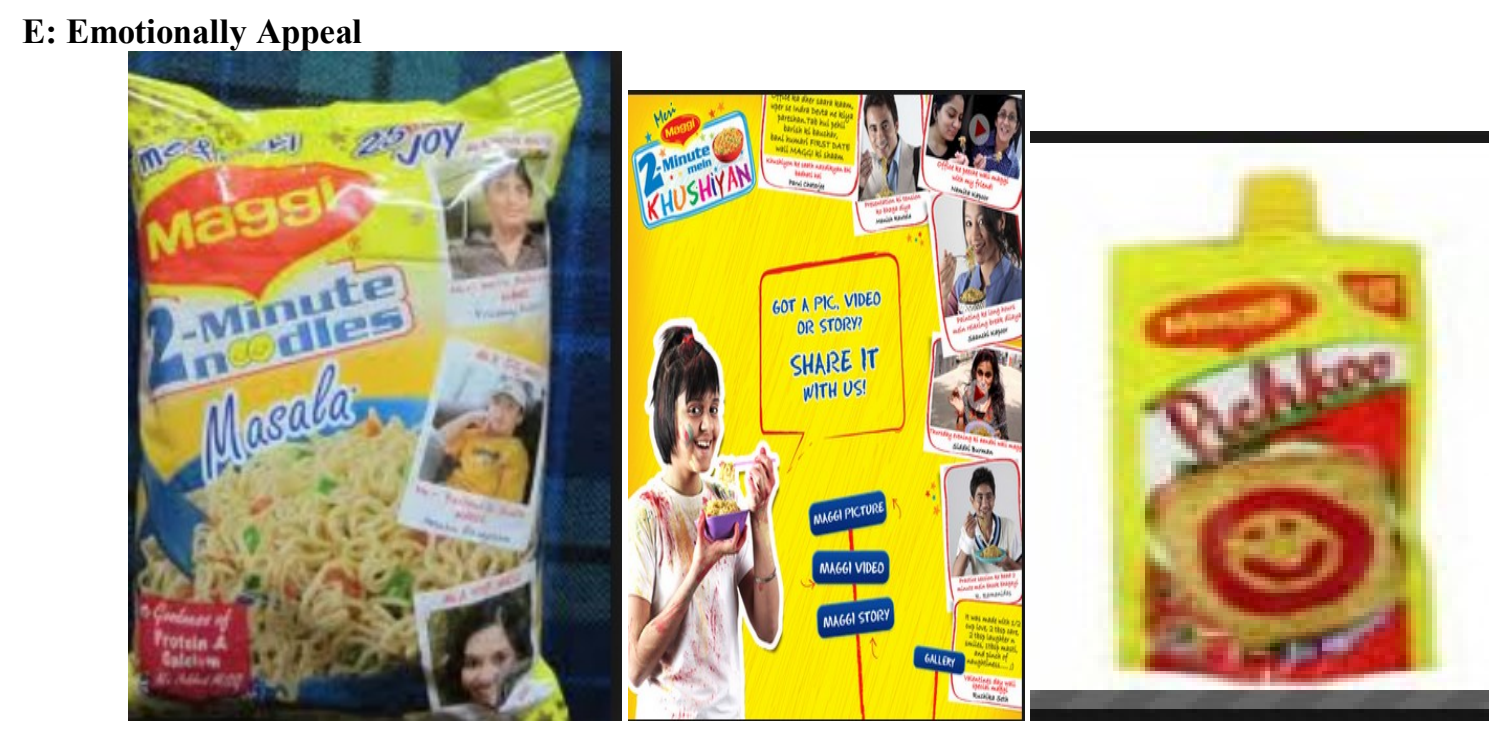

Marketers are adding emotional appeal to the product package. Meri maggi, for instance, associates the the emotions of the customer by sharing different stories of the customers through its pack.

Psychological tricks are used by the marketers to influence the behavior of the consumers which may include designing new look, Convenience in use, different size packaging(sachets to large packs), sharp graphic elements can create joyful moments for the customer, which in-turn converts the intention- to- buy in the final purchase or repurchase of the product. Advertising researchers (Cramphorn, 2006; Penn, 2006) feel that emotions and feelings are often confused. They note that emotions are short-term, unconscious and influence feelings while feelings are conscious, cognitive and can be self-reported. Do different kinds of packaging evoke different emotions in consumers? For instance Maggi Pichkoo sauce which the company launched in 15 gms was famous due to ease to carry \& convenience to use, created many joyful \& satisfactory moments in the customers.

Remember 'combo meal' or 'value meal' in McDonalds or in other fast food restaurants where instead of buying a burger, a drink, \& fries seperately they are offered to you in a complete package a "combo". "Happy meal' is very famous in children as it offers a toy with the complete package.

The package must have a emotional appeal besides being attractive. The important thing is to design and develop a comprehensive look and feel that is truly in sync with the overall brand identity.

\section{A: Aesthetic}

Aesthetic design, through graphics (e.g. colour, typeface, images) and structural elements (e.g., shape, size, and materials) has the ability to produce emotions and related physiological responses, which are universal and involuntary (Hine, 1995)

Folkes and Matta (2004) find that unusually shaped containers that attract attention are perceived to contain more product than containers that do not attract attention.

In addition, aesthetics represents beauty, good taste, or an appreciation of color and form. As everyone knows, good design can catch the attention of consumers and create strong competitiveness in the target market. Thus, product design is very important to marketers. (Philip Kotler et al. 2005 pp. 546-549). In addition, the color selections are also influenced by trends; sometimes consumers follow the fashion trends in selecting colors.(Michael R. Solomon 1996 pp. 58-66).For example, blue and green are felt cool and security; red and yellow are felt warm and cheerful; black is regarded as a symbol of strength. Thus, consumer behavior can be influenced by using suitable color in packaging design (David Jobber 2001 pp. 74-75).

The company should design the packaging that covers specific elements, such as size, shape, materials, color, pattern, text and brand mark. (Philip Kotler et al. 2005p.550).

\section{L: Logical}

There are instances where packaging has rejuvenated the brand from ill-health through its cognitive power. For instance, Heinz worked extensively to redesign its ketchup bottle so that it could stand upside down. 
This made for easy use as the ketchup was always near the opening \& the vaccum seal also helped eliminate mess. Twedt (1968) urges that "the potential contribution of a superior package to profitability is simply too great to be ignored." Zip packages, for instance, which are used to wrap different snack items is a logical way of designing a package to the product as it provides ease of use, the product can be left in the same pack after consumption with the zip closed for further use.

\section{Conclusion}

Packaging is used as a marketing tool not only to give protection to a product but also to impart visual presence, uniqueness to the product. Now a days the consumers not only wants the package to serve the basic function but something more. Hence the meaning of packaging has been changed. It is not only to provide a basic wrap to the product but also to provide a more intellectual, distinct, aesthetic $\&$ logical wrap to the product with an emotional appeal attached to it.

\section{References:}

[1]. Volpe and Koenig, P.C. Protecting Your Innovations: Obtaining, Maintaining and Sustaining Intellectual Property Rights in Your Brand, Prodcuts and Proceses, prepared for the Institute of Food Technologists Annual Meeting and Food Expo, 2006.

[2]. Philip Kotler, Gary Armstrong (2008) Principles of Marketing, 12th edition, Pearson Education Inc.

[3]. David Jobber (2001) Principles \& Practice of Marketing, 3rd edition, McGraw-Hill Publishing Company.

[4]. Philip Kotler, Veronica Wong, John Saunders, Gary Armstrong (2005) Principles of Marketing, 4th European edition, Pearson Education Limited.

[5]. Fitzsimons, Gavan J., J. Wesley Hutchinson, Patti Williams, Joseph W. Alba, Tanya L.Chartrand, Joel Huber, Frank R. Kardes, Geeta Menon, Priya Raghubir, J. Edward Russo, Baba Shiv, and Nader T. Tavassoli (2002), "Non-Conscious Influences on Consumer Choice,"Marketing Letters, 13:3, 269-279.

[6]. Folkes, Valerie and Shashi Matta (2004), "The Effect of Package Shape on Consumers'Judgments of Product Volume: Attention as a Mental Contaminant," Journal of ConsumerResearch, 31 (2), 390-401.

[7]. Silayoi and Speece (2004), Packaging \& Purchase Decisions, British Food Journal, Vol 106 no.8 pp.607-628 